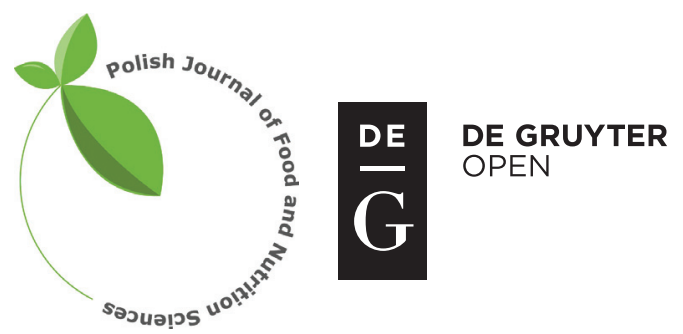

Pol. J. Food Nutr. Sci., 2017, Vol. 67, No. 4, pp. 301-308 DOI: $10.1515 /$ pjfns-2016-0029 http://journal.pan.olsztyn.pl

Original research article

Section: Food Chemistry

\title{
Evaluation of Seasonal Variations in the Glucosinolate Content in Leaves and Roots of Four European Horseradish (Armoracia rusticana) Landraces
}

\author{
Ewa Ciska ${ }^{1 *}$, Marcin Horbowicz' ${ }^{2}$, Maria Rogowska ${ }^{3}$, Ryszard Kosson ${ }^{4}$, Natalia Drabińska ${ }^{1}$, Joanna Honke \\ ${ }^{\prime}$ Department of Chemistry and Biodynamics of Food, Institute of Animal Reproduction and Food Research \\ of Polish Academy of Sciences, Tuwima 10, 10-747 Olsztyn, Poland \\ ${ }^{2}$ Department of Plant Physiology and Genetics, Siedlce University of Natural Sciences and Humanities, \\ 08-110 Siedlce, Prusa 12, Siedlce, Poland \\ ${ }^{3}$ State Higher Vocational School, Batorego 64C, 96-100 Skierniewice, Poland \\ ${ }^{4}$ Research Institute of Horticulture, Konstytucji 3 Maja 1/3, 96-100 Skierniewice, Poland
}

Key words: horseradish, glucosinolate composition, growing season, leaves, roots

In comparison with other cruciferous vegetables, horseradish has rarely been the object of scientific research, and the knowledge about the composition, content and distribution of glucosinolates (GLS) in different organs of horseradish plants is limited. Therefore, the aim of this study was to evaluate changes in the GLS content in leaves and roots of four horseradish landraces during the growing season.

The presence of 13 GLS was determined in the examined horseradish tissues, and glucoraphanin, glucoraphenin and napoleiferin were noted for the first time in the species. During the growing season, the content of individual GLS changed significantly. The rate and direction of these changes varied across the examined landraces and plant organs. In the leaves, between May and June, the content of sinigrin, the main GLS in all horseradish landraces, decreased in Bavarian (40\%) and Hungarian (11\%) horseradish, increased (22\%) in Creamy horseradish, whereas in Danish horseradish, the difference was not significant. Despite the changes observed in the first two months, the highest content of sinigrin was noted in July in all horseradish landraces. During the growing season (August-October), the content of sinigrin fluctuated in the roots of Creamy and Danish landraces, reaching the highest level in October and September, respectively, whereas in the roots of Hungarian and Bavarian landraces, sinigrin concentrations continued to increase and peaked in October. Changes in the content of other, minor GLS during the growing season often differed from those noted in sinigrin levels.

\section{INTRODUCTION}

Horseradish (Armoracia rusticana Gaertn., C.A. Mey \& Scherb) is a perennial and neglected plant cultivated mainly for its roots. Grated horseradish is characterised by a hot and spicy flavour, and is used as a condiment in many countries around the world [Wedelsbäck Bladh \& Olsson, 2011]. The characteristic taste and aroma of horseradish are associated with the presence of sulphur glucosides known as glucosinolates (GLS) [Agneta et al., 2013]. Glucosinolates are found in vacuoles of plant cells, and they are separated from myrosinase (EC 3.2.3.1), a membrane-bound enzyme, until cell damage [Redovnikovic et al., 2008]. When horseradish tissue is damaged during grating or cutting, the enzyme is released and fused with GLS. The enzymatic hydrolysis of GLS results in the formation of various compounds, mostly isothiocyanates, as well as smaller amounts of nitriles, thiocyanates, epithionitriles, and oxazolidines [Agerbirk \& Olsen, 2012]. The breakdown products are responsible for the taste and aroma of horseradish. For instance, sinigrin undergoes

\footnotetext{
* Corresponding Author: E-mail: e.ciska@pan.olsztyn.pl (Dr. E. Ciska)

enzymatic degradation to form allyl isothiocyanate which has a bitter taste, a pungent odour and causes lachrymation [Horbowicz \& Rogowska, 2006; Kosson \& Horbowicz, 2009; Wedelsbäck Bladh et al., 2013].

To date, nearly 130 GLS have been identified [Agerbirk \& Olsen, 2012], including around only 20 in vegetables. The type and concentration of GLS in plants vary considerably subject to genetic traits [Fahey et al., 2001], climate [Ciska et al., 2000] and agronomic factors such as sulphur and nitrogen fertilization [Alnsour 2013; De Maria et al., 2016]. GLS can be divided into aliphatic, aralkyl and indole group. Horseradish is one of the richest sources of GLS [Fahey et al., 2001; Li \& Kushad, 2004; Agneta et al., 2012, 2014; Alsnour, 2013]. Seventeen GLS have been identified in horseradish to date [Agneta et al., 2014]. Sinigrin is an aliphatic GLS and is the main GLS in horseradish, followed by gluconasturtiin and glucobrassicin, as aralkyl and indole GLS, respectively, while the content of other GLS is marginal. The content of other GLS, both aliphatic and indole, is minimal. Differences in GLS profiles and content were observed between horseradish accessions and between plant organs. According to Li \& Kushad [2004], the total GLS content in the roots 
of 27 horseradish accessions and the leaves of 9 accessions ranged from 2 to $296 \mu \mathrm{mol} / \mathrm{g}$ DW and from 34 to $201 \mu \mathrm{mol} / \mathrm{g}$ DW, respectively. The noted variations could also be attributed to the growth stage [Li \& Kushad, 2004; Alnsour, 2013]. It is assumed that younger tissues are a richer source of indole GLS than senescent tissues [Mevy et al., 1997].

The interest in GLS and their breakdown products has been spurred by their biological activity. These compounds play a very important role in plants by protecting them from herbivores and pathogens [Appel \& Cocroft, 2014]. Glucosinolate breakdown products deliver health benefits also for humans. Numerous studies have demonstrated that isothiocyanates [Higdon et al., 2007] and selected nitriles have anticarcinogenic effects [Tanii et al., 2008; Hanschen et al., 2015].

Horseradish is considered as the richest source of sinigrin in a human diet [Agneta et al., 2013]. Allyl isothiocyanate, the main breakdown product of sinigrin, has been shown to have several biological activities. Antimicrobial [Shin et al., 2004] and anticancer activity related to multimode mechanism of action [Xiao et al., 2003; Zhang et al., 2010], including the stimulation of cytoprotective protein and anti-inflammatory activity, have been reported in the previous studies [Wagner et al., 2012]. The biological activity of horseradish has been discovered many centuries ago, and it was very often utilized for treatment purposes in the traditional medicine [Agneta et al., 2013].

The use of horseradish as food is most wide spread in the Eastern and Mediterranean part of Europe [Wedelsback Bladh \& Olsson, 2011]. The roots are used to flavour and preserve the plant food, or to support the vegetable fermentation [Sampliner \& Miller, 2009]. Grated root is very popular as a condiment to cooked meat. The horseradish leaves can be used for salad and placed in the oven under baking bread to flavour and to prevent it from sticking.

The knowledge about the composition, content and distribution of GLS in different organs of horseradish plants is limited [Li \& Kushad, 2004; Agneta et al., 2014]. Various authors have recognized the need to examine GLS concentrations in intermediate periods of horseradish development [Agneta et al., 2014]. Therefore, the aim of this study was to evaluate changes in the GLS content in leaves and roots in different horseradish accessions during the growing season.

\section{MATERIALS AND METHODS}

\section{Plant material}

The experimental material consisted of 4 horseradish landraces: Bavarian, Danish, Hungarian, and Creamy. White horseradish (Bavarian, Danish and Hungarian) has white, cylindrically-shaped roots and dark green, strongly toothed leaves. Creamy horseradish has light yellow, slightly conical roots and green, somewhat toothed leaves. All landraces originated from the south-western part of the Łódź Region, the centre of horseradish production in Poland.

\section{Horseradish cultivation}

Horseradish seedlings were obtained by vegetative multiplication of original accessions in 2004. They were planted in 2005 between 10 and 20 of April in the experimental fields of the Research Institute of Horticulture in Skiernie- wice, Poland (geographical coordinates: N51 ${ }^{\circ} 57^{\prime} 50.1139^{\prime \prime}$ E20 $9^{\prime} 49.6166$ "). The cultivation experiment was conducted on sandy loam soil with $\mathrm{pH} 5.7-6.0$ and $1.7 \%$ organic matter content. Before planting, soil was fertilised with urea ( $80 \mathrm{~kg} \mathrm{~N} / \mathrm{ha})$, superphosphate $\left(125 \mathrm{~kg} \mathrm{P}_{2} \mathrm{O}_{5} / \mathrm{ha}\right)$ and potassium $(250 \mathrm{~kg} \mathrm{~K}$ O/ha); potassium nitrate $(60 \mathrm{~kg} \mathrm{~N} / \mathrm{ha})$ was applied during rapid growth. Weeds were removed manually, and the crops were watered according to need. Each type of horseradish was grown on 4 plots $\left(15 \mathrm{~m}^{2}\right.$ each, 75 plants per plot) with a randomised block design. The distance between rows was $67.5 \mathrm{~cm}$ and within rows was $5 \mathrm{~cm}$.

\section{Sample preparation}

Horseradish leaves were sampled for analysis from May to August (in the middle of each month; between 9 and 10 a.m.). Leaf sampling stopped in August due to leaf aging and yellowing. Root samples were collected from August to October. For analyses of the GLS content in leaves, one leaf was collected from 12 plants in one replication (around 50-100 g). A quarter of the central part of roots (around $100 \mathrm{~g}$ ) was collected for GLS analysis. Plant samples were immediately frozen at $-25^{\circ} \mathrm{C}$ and lyophilised using the Christ Alpha 1-2LD plus laboratory freeze-dryer (Osterode am Harz, Germany).

\section{GLS analysis}

The isolation, desulphatation and HPLC separation of GLS were carried out according to the guidelines of the Commission of European Communities [1990], as previously described by Ciska et al. [2008]. The separation was performed using the HPLC system with an autosampler (LC-10, Shimadzu, Japan) and a UV-VIS detector (SPD-10A, Shimadzu, Japan) using the LiChrospher ${ }^{\circledR} 100 \mathrm{RP}-18(250 \times 4 \mathrm{~mm}$; $5 \mu \mathrm{m})$ column (Merck). Desulpho-GLS was separated with a gradient of water (A) and 20\% acetonitrile (B) as previously described [Ciska et al., 2008]. Glucosinolates were identified by comparing their retention times with those of known reference compounds or on the basis of available literature data. The presence of aliphatic GLS not having a standard was also additionally confirmed with the GC-MS analysis of respective degradation products using a gas chromatograph Agilent 7890A equipped with a mass detector 5975C VL, as described earlier [Ciska \& Pathak, 2004]. Glucotropaeolin (Merck, Darmstadt, Germany) was used as the internal standard for quantification. All experiments and analytical measurements were performed in triplicate. The sample content of GLS was quantified based on the internal standard and relevant relative response factors [Commission of European Communities, 1990]. Data were processed with the use of standard statistical procedures, and the least significant difference between means was calculated using the Newman-Keuls test at $\mathrm{p}<0.05$.

\section{RESULTS AND DISCUSSION}

Thirteen GLS, including nine aliphatic, three indole and one aryl GLS, were identified in the analysed horseradish. For all landraces, the concentrations of these compounds during the growing season (from May to August in leaves, and from August to October in roots) are presented in Tables 1-4. The presence of nine GLS in horserad- 


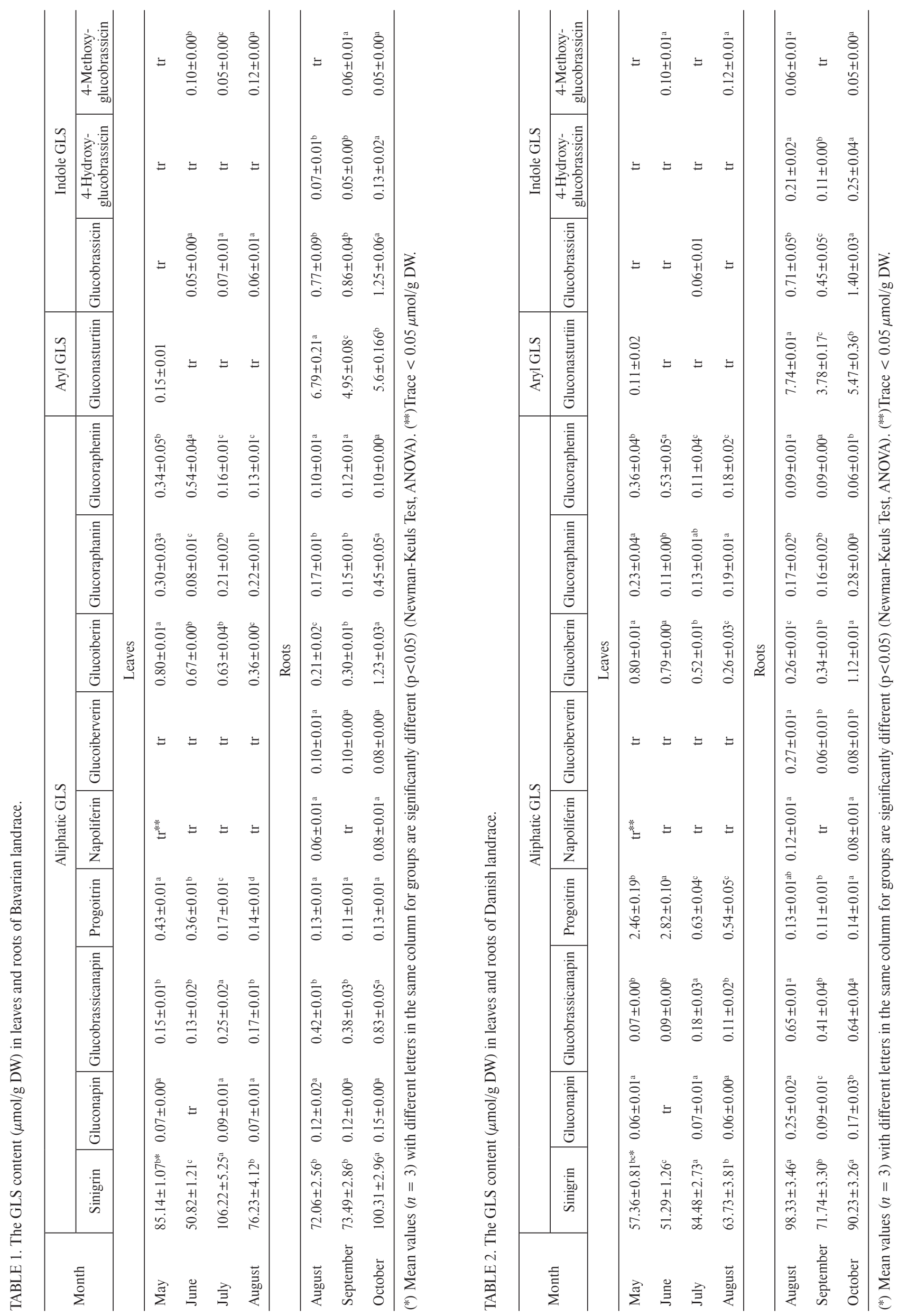




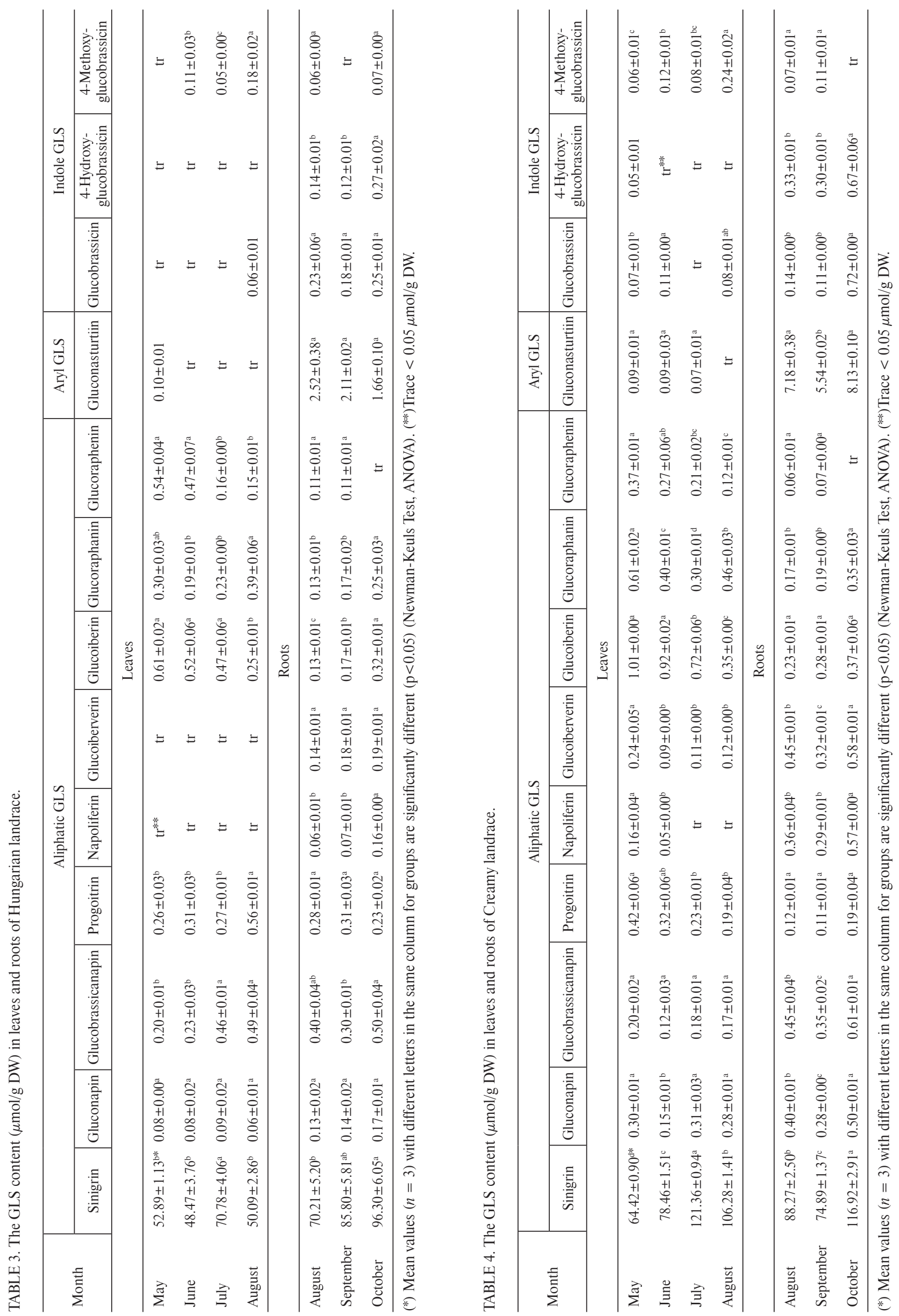


ish: sinigrin, glucoiberin, gluconapin, glucobrassicanapin, progoitrin, gluconasturtiin, glucobrassicin, 4-hydroxyglucobrassicin and 4-methoxyglucobrassicin, was confirmed by other researchers [Li \& Kushad, 2004; Agneta et al., 2012; Wedelsbäck Bladh et al., 2013]. Glucoiberverin (identified only based on the corresponding mustard oils) was also identified by Grob \& Matile [1980], whereas the presence of glucoraphanin, glucoraphenin and napoleiferin was noted in horseradish for the first time.

In all analysed landraces, sinigrin was the predominant GLS in both leaves and roots in all growth stages. In the leaves, the percentage of sinigrin in total GLS content varied from $92 \%$ in Danish horseradish in June to more than 98\% in Creamy and Bavarian horseradish in July and August, and in the Danish accession in July. In the roots, the highest content of sinigrin (94-96\%) was observed in the Hungarian landrace, and the lowest content (89\%) was noted in Creamy and Bavarian horseradish in August. Other researchers also reported high sinigrin levels in the leaves and roots of horseradish [Li \& Kushad, 2004; Redovniković et al., 2008; Alnsour, 2013].

Sinigrin concentrations fluctuated across growth stages. At the first stage of leaf growth (May to June), sinigrin content decreased by $40 \%$ and $11 \%$ in Bavarian and Hungarian horseradish, respectively, but increased by $22 \%$ in the Creamy accession (Table 1). In Danish horseradish, the observed difference in the sinigrin content in leaves was not statistically significant, but a decreasing trend was noted. At successive stages of development (July-August), sinigrin concentrations increased significantly in July and decreased in August in all horseradish landraces. In July, the highest 2-fold increase in sinigrin levels was observed in Bavarian horseradish, whereas the smallest $46 \%$ increase was noted in the Hungarian type. In August, sinigrin concentrations decreased by $20-29 \%$ in Bavarian, Danish and Hungarian landraces, and by only $12 \%$ in Creamy horseradish.

The decrease in the sinigrin content in all horseradish landraces, excluding Creamy, at the first stage of development (May-June) most probably resulted from dilution of sinigrin in growing leaves [Cleembut \& Becker, 2012]. Changes in the GLS content of both leaves and roots during the growing season have not been investigated to date. For this reason, the distinct profile of changes in the sinigrin content in the Creamy landrace is difficult to explain without more extensive research. The unexpected increase in sinigrin concentrations observed in June only in Creamy landrace could be attributed to genetic factors which would also be responsible for differences in the growth rate and/or the rate of GLS accumulation. Therefore, it is possible that the drop in GLS concentrations, which was observed in Bavarian, Danish and Hungarian landraces in June, took place later or earlier in Creamy horseradish and remained unnoticed because the samples were analysed only once a month.

Agneta et al. [2014] and Mølmann et al. [2015] also reported high levels of aliphatic GLS in photosynthetic tissues, which indicates that the rate of photosynthesis is related to GLS content. Other authors also found that light can induce the expression of genes involved in GLS biosynthesis [Huseby et al. 2013].
Sinigrin content gradually increased in the roots of Bavarian and Hungarian landraces. In Danish and Creamy horseradish, sinigrin concentrations fluctuated throughout the growing season (August-October) and were lowest in September.

In our study, the decrease in sinigrin levels at the last stage of leaf development (August) and the increase in the GLS content in roots in October could be caused by the aging of above-ground tissues or the transfer of GLS from leaves to roots [Chen \& Andreasson, 2001]. Similar results were reported by Alnsour [2013] who noted a rapid drop in GLS concentrations in fully matured horseradish leaves at the end of the growing season. The above authors attributed their findings to active translocation of GLS between leaves and roots, the sink organs of a plant. Previous studies suggested that the transport of GLS follows the allocation of assimilates and that intact GLS have properties that satisfy the permeability criterion for phloem mobility [Chen et al., 2001]. The cited authors concluded that GLS are readily loaded into and transported by the phloem. Phloemmediated transport of GLS may coordinate de novo biosynthesis and promote the use of GLS as defence compounds in various organs. Recent studies demonstrated the presence of GLS in the root xylem sap of Arabidopsis, which indicates that a transport pathway is involved in root-to-shoot GLS allocation [Madsen et al., 2014; Jørgensen et al., 2015]. In contrast, Li et al. [1999] did not report correlations between the GLS content in the leaves, stems and roots of Brassica napus, and they concluded that both synthesis and accumulation of GLS are controlled by plant tissues. A similar explanation for the lack of correlations between individual GLS in horseradish leaves and roots was proposed by Li \& Kushad [2004].

In addition to the predominant sinigrin, significant quantities of gluconasturtiin were found in the roots of all horseradish landraces, and the leaves of Danish horseradish were abundant in progoitrin. During the growing season, the gluconasturtiin content in roots fluctuated in Creamy, Bavarian and Danish horseradish. Gluconasturtiin concentrations decreased in September and increased in October. In Creamy horseradish, the content of gluconasturtiin at harvest maturity was even higher than at the beginning of root development, reaching $8.13 \mu \mathrm{mol} / \mathrm{g}$ DW, i.e. the highest value noted in all accessions. In Hungarian landrace a decreasing tendency was observed, however the differences were not significant. The studied horseradish landraces contained only trace amounts of gluconasturtiin in leaves. Li \& Kushad [2004] also reported higher gluconasturtiin levels in horseradish roots than leaves. Unlike the remaining horseradish landraces, the Danish landrace was characterised by a relatively high content of progoitrin in the leaves. The highest progoitrin levels were observed in May $(2.46 \mu \mathrm{mol} / \mathrm{g}$ DW) and June $(2.82 \mu \mathrm{mol} / \mathrm{g} \mathrm{DW})$ when they accounted for nearly $4 \%$ of total GLS content. The content of progoitrin decreased by $78 \%$ between June and July. In the leaves of other landraces, progoitrin concentrations did not exceed $0.4 \mu \mathrm{mol} / \mathrm{g}$ DW. The relatively high progoitrin content in Danish horseradish and low progoitrin levels in other landraces point to genetic differentiation of horseradish. In a study by Wedelsbäck Bladh et al. 
[2013], measurable amounts of progoitrin were detected in only 2 of 168 accessions of Nordic horseradish.

In addition to major GLS, the analysed horseradish landraces also contained small amounts of aliphatic GLS such as glucoiberin, glucoiberverin, glucoraphanin, glucoraphenin, napoleiferin, gluconapin and glucobrassicanapin in roots and leaves. During the growing season, the pattern of changes in the concentrations of aliphatic GLS often differed from that of the major GLS such as sinigrin and gluconasturtiin. Those differences can probably be attributed to the common biosynthesis pathways of individual compounds. Glucosinolates with three carbon atoms in a side chain, including sinigrin, glucoiberverin and glucoiberin, belong to the same biosynthesis pathway which is regulated by 2-oxoglutarate-dependent dioxygenases. Therefore, sinigrin levels are determined by the content of the precursor glucoiberin which, in turn, depends on glucoiberverin concentrations [Magrath et al., 1994; Ishida et al., 2014]. In our study, such relationships between individual GLS were observed between May and July when sinigrin content increased and the concentrations of glucoiberin and glucoiberverin decreased. The fluctuations in the levels of progoitrin, gluconapin and glucoraphanin resulting from S-oxygenation can be also explained by the fact that those four-carbon side-chain GLS belong to the same biosynthetic pathway [Magrath et al., 1994; Ishida et al., 2014].

Indole GLS, glucobrassicin, 4-hydroxy-glucobrassicin and 4-methoxy-glucobrassicin, were also found in both leaves and roots of the analysed horseradish plants. Leaves often contained trace amounts of these compounds, but in the roots of all horseradish landraces, the concentrations of indole GLS increased or tended to increase throughout the growing season. As a result, the glucobrassicin content in roots was relatively high at harvest maturity, and in Danish and Bavarian landraces exceeded even $1 \mu \mathrm{mol} / \mathrm{g}$ DW. Our results contradict most published findings which suggest that indole GLS levels are higher in younger tissues [Mevy et al., 1997]. Some authors placed glucobrassicin in the group of predominant GLS [Li \& Kushad, 2004], but in our study, the proportion of glucobrassicin in total GLS varied across landraces and was predominant only in Danish and Bavarian horseradish.

\section{CONCLUSIONS}

GLS in Brassicaceae plants are well described in the literature. However, as compared to other vegetables belonging to this family, the GLS pattern in horseradish has been relatively poorly characterised. Therefore, novel compounds that belong to the GLS group are still being discovered during studies of horseradish plants. A total of 13 GLS were found in the horseradish landraces examined in this study. Glucoraphanin, glucoraphenin and napoleiferin were noted in horseradish tissues for the first time.

In our study, the content of individual GLS in horseradish fluctuated significantly during the growing season, and the rate and direction of these changes varied across the analysed landraces. At the first stage of leaf growth (May to June), the content of sinigrin, the main GLS in horserad- ish, decreased by $40 \%$ and $11 \%$ in Bavarian and Hungarian horseradish, respectively and increased by $22 \%$ in the Creamy landrace. In Danish landrace, the difference in the sinigrin content in leaves was not statistically significant. Despite the differences noted in the first two months, sinigrin concentrations in all horseradish types peaked in July, probably due to a higher rate of photosynthesis. Further studies are needed to confirm the effect of temperature, sun exposure and photoperiod on GLS accumulation in horseradish in July.

Similarly to leaves, changes in the sinigrin content of roots were also observed in horseradish landraces during the growing season (August - October). Sinigrin content increased gradually in the roots of Hungarian and Bavarian landraces, and it fluctuated in Creamy and Danish types.

In our study, the fluctuations in the levels of other, minor GLS followed a different pattern than the changes in sinigrin levels. The differences in the direction and rate of changes in individual GLS during the growing season can probably be attributed to mutual relationships between GLS belonging to the same biosynthesis pathways. However, further research is required to confirm this hypothesis.

Among all the Brassica vegetables consumed by humans, horseradish is the richest source of the precursor of beneficially active isothiocyanates - sinigrin. Therefore, the intake of this plant, not only as a condiment made from root but also in the form of leaves containing even more sinigrin than the roots, should be propagated in the human diet. Horseradish leaves may be a valuable additive to salads, simultaneously enhancing the attractiveness and supplementing our diet with minerals, vitamins and fibre, as well as in compounds having a potential anticancer activity.

\section{RESEARCH FUNDING}

Research were supported by the Ministry of Science and Higher Education (Poland) as part of the statutory activities of the Research Institute of Horticulture, Skierniewice (Poland).

\section{CONFLICT OF INTEREST}

Authors declare no conflict of interest.

\section{REFERENCES}

1. Agerbirk N., Olsen C.E. Glucosinolate structures in evolution. Phytochemistry, 2012, 77, 16-45.

2. Agneta R., Lelario F., De Maria S., Möllers C., Bufo S.A., Rivelli A.R., Glucosinolate profile and distribution among plant tissues and phenological stages of field-grown horseradish. Phytochemistry, 2014, 106, 178-187.

3. Agneta R., Mollers C., Rivelli A.R., Horseradish (Armoracia rusticana), a neglected medical and condiment species with a relevant glucosinolate profile: a review. Genet. Resour. Crop Evol., 2013, 60, 1923-1943.

4. Agneta R., Rivelli A.R., Ventrella E., Lelario F., Sarli G., Bufo S.A., Investigation of glucosinolate profile and qualitative aspects in sprouts and roots of horseradish (Armoracia rusticana) using LC-ESI-hybrid linear ion trap with Fourier transform ion 
cyclotron resonance mass spectrometry and infrared multiphoton dissociation. J. Agric. Food Chem., 2012, 60, 7474-7482.

5. Alnsour M., Influence of exogenous factors on glucosinolate accumulation in horseradish (Armoracia rusticana Gaertn., Mey. \& Scherb.). PhD thesis. Braunschweig University of Technology, 2013. [http://rzbl04.biblio.etc.tu-bs.de:8080/docportal/servlets/ MCRFileNodeServlet/DocPortal_derivate_00029574/Thesis.pdf ;jsessionid=1B8F50A662E70ABEC049B33955733266].

6. Appel H.M., Cocroft R.B., Plants respond to leaf vibrations caused by insect herbivore chewing. Oecologia, 2014, 175, 1257-1266 .

7. Chen S., Andreasson E., Update on glucosinolate metabolism and transport. Plant Physiol. Biochem., 2001, 39, 743-758.

8. Chen S.X., Petersen B.L., Olsen C.E., Schulz A., Halkier B.A., Long-distance phloem transport of glucosinolates in Arabidopsis. Plant Physiol., 2001, 127, 194-201.

9. Ciska E., Honke J., Kozłowska H., Effect of light conditions on the contents of glucosinolates in germinating seeds of white mustard, red radish, white radish, and rapeseed. J. Agric. Food Chem., 2008, 56, 9087-9093.

10. Ciska E., Martyniak-Przybyszewska B., Kozłowska H., Content of glucosinolates in cruciferous vegetables grown at the same site for two years under different climatic conditions. J. Agric. Food Chem., 2000, 48, 2862-2867.

11. Ciska E., Pathak D., Glucosinolate derivatives in stored fermented cabbage. J. Agric. Food Chem., 2004, 52, 7938-7943.

12. Cleemput S., Becker H., Genetic variation in leaf and stem glucosinolates in resynthesized lines of winter rapeseed (Brassica napus L.). Gen. Res. Crop Evol., 2012, 59, 539-546.

13. Commission of the European Communities (1990). Commission Regulation (EC) No 1864/90 of 29 June 1990 amending Regulation (EEC) No 147/68 on the drawing and reduction of samples and on methods of analysis in respect of oil seed. Brussels: Official Journal of the European Communities. L 170/27-L 170/34.

14. De Maria S., Agneta R., Lelario F., Möllers C., Rivelli A.R., Influence of nitrogen and sulfur fertilization on glucosinolate content and composition of horseradish plants harvested at different development stages. Acta Physiol. Plant, 2016, 38, 91.

15. Fahey J.W., Zalcmann A.T., Talalay P., The chemical diversity and distribution of glucosinolates and isothiocyanates among plants. Phytochemistry, 2001, 56, 5-51.

16. Grob K., Matile P., Capillary GC of glucosinolate-derived horseradish constituents. Phytochemistry, 1980, 19, 1789-1793.

17. Hanschen F.S., Herz C., Schlotz N., Kupke F., Bartolome Rodriguez M.M., Schreiner M., Rohn S., Lamy E., The Brassica epithionitrile 1-cyano-2,3-epithiopropane triggers cell death in human liver cancer cells in vitro. Mol. Nutr. Food Res., 2015, 59, 2178-2189.

18. Higdon J.V., Delage B., Williams D.E., Dashwood R.H., Cruciferous vegetables and human cancer risk: epidemiologic evidence and mechanistic basis. Pharmacol. Res., 2007, 55, 224-36.

19. Horbowicz M., Rogowska M., Content of isothiocyanates and flavonols in roots during vegetation of two types horseradish. Veg. Crops Res. Bull., 2006, 65, 95-104.

20. Huseby S., Koprivova A., Lee B.R., Saha S., Mithen R., Wold A.B., Bengtsson G.B., Kopriva S., Diurnal and light regulation of sulphur assimilation and glucosinolate biosynthesis in Arabidopsis. J. Exp. Bot., 2013, 64, 1039-1048.
21. Ishida M., Hara M., Fukino N., Kakizaki T., Morimitsu Y., Glucosinolate metabolism, functionality and breeding for the improvement of Brassicaceae vegetables. Breed. Sci., 2014, 64, $48-59$.

22. Jørgensen M.E., Nour-Eldin H.H., Halkier B.A., Transport of defense compounds from source to sink: lessons learned from glucosinolates. Trends Plant Sci., 2015, 20, 508-514.

23. Kosson H., Horbowicz M., Some quality characteristics including isothiocyanates content in horseradish cream as affected by storage period. Veg. Crops Res. Bull., 2009, 71, 123-132.

24. Li X., Kushad M.M., Correlation of glucosinolate content to myrosinase activity in horseradish (Armoracia rusticana). J. Agric. Food Chem., 2004, 52, 6950-6955.

25. Li Y.C., Kiddle G., Bennett R., Doughty K., Wallsgrove R., Variation in the glucosinolate content of vegetative tissues of Chinese lines of Brassica napus L. Ann. Appl. Biol., 1999, 134, 131-136.

26. Madsen S.R., Olsen C.E., Nour-Eldin H.H., Elucidating the role of transport processes in leaf glucosinolate distribution. Plant Physiol., 2014, 166, 1450-1462.

27. Magrath R., Bano F., Morgner M., Parkin I., Sharpe A., Lister C., Dean C., Turner J., Lydiate D., Mithen R., Genetics of aliphatic glucosinolates. I. Side chain elongation in Brassica napus and Arabidopsis thaliana. Heredity, 1994, 72, 290-299.

28. Mevy J.P., Rabier J., Quinsac A., Krouti M., Ribaillier D., Glucosinolate contents of regenerated plantlets from embryoids of horseradish. Phytochemistry, 1997, 44, 1469-1471.

29. Mølmann J.A.B., Steindal A.L.H., Bengtsson G.B., Seljasen R., Lea P., Skaret J., Johansen T.J., Effects of temperature and photoperiod on sensory quality and contents of glucosinolates, flavonols and vitamin C in broccoli florets. Food Chem., 2015, 172, $47-55$.

30. Redovniković R.I., Peharec P., Krsnik-Rasol M., Delonga K., Brkić K., Vorkapić-Furač J., Glucosinolate profiles, myrosinase and peroxidase activity in horseradish (Armoracia lapathifolia Gilib.) plantlets, tumour and teratoma tissues. Food Technol. Biotech., 2008, 46, 317-321.

31. Sampliner D., Miller A., Ethonobotany of horseradish (Armoracia rusticana, Brassicaceae) and its wild relatives (Armoracia $s s p$.): reproductive biology and local uses in their native ranges. Econ. Bot., 2009, 63, 303-313.

32. Shin I.S., Masuda H., Naohide K., Bactericidal activity of wasabi (Wasabia japonica) against Helicobacter pylori. Int. J. Food Microbiol., 2004, 94, 255-261.

33. Tanii H., Higashi T., Nishimura F., Higuchi Y., Saijoh K., Effects of cruciferous allyl nitrile on phase 2 antioxidant and detoxification enzymes. Med. Sci. Mon., 2008, 14, 189-92.

34. Wagner A.E., Boesch-Saadatmandi C., Dose J., Schultheiss G., Rimbach G., Anti-inflammatory potential of allyl isothiocyanate - role of Nrf2, NF- $\mathrm{B}$ and microRNA-155. J. Cell Mol. Med., 2012, 16, 836-843.

35. Wedelsbäck Bladh K., Olsson K.M., Introduction and use of horseradish (Armoracia rusticana) as food and medicine from antiquity to the present: emphasis on the Nordic countries. J. Herbs Spices Med. Plants, 2011, 17, 197-213.

36. Wedelsbäck Bladh K., Olsson K.M., Yndgaard F., Evaluation of glucosinolates in Nordic horseradish (Armoracia rusticana). Bot. Lithuanica, 2013, 19, 48-56.

37. Xiao D., Srivastava S.K., Lew K.L., Zeng Y., Hershberger P., Johnson C.S., Trump D.L., Singh S.V., Allyl isothiocyanate, 
a constituent of cruciferous vegetables, inhibits proliferation of human prostate cancer cells by causing G2/M arrest and inducing apoptosis. Carcinogenesis, 2003, 24, 891-897.
38. Zhang Y., Allyl isothiocyanate as a cancer chemopreventive phytochemical. Mol. Nutr. Food Res., 2010, 54, 127-135.

Submitted: 10 March 2016. Revised: 13 June 2016. Accepted: 15 July 2016. Published on-line: 19 January 2017. 